\title{
Communication aids in patients with motor neurone disease
}

\author{
ALISON R PERRY，MAREK GAWEL，F CLIFFORD ROSE
}

\begin{abstract}
The study aimed at determining the main factors responsible for the speech and communication problems in motor neurone disease to try to assess the suitability of commercially available aids. Sixteen patients suffering from motor neurone disease with communication problems had their speech assessed by using the Frenchay dysarthria assessment. It was found essential to offer a choice of aids to the patient since suitability of a particular aid could not be evaluated without the patient practising with it.
\end{abstract}

\section{Introduction}

Motor neurone disease is a disorder causing loss of anterior horn cells and pyramidal tracts, which results in lower motor neurone and upper motor neurone muscle weakness respectively. If the disorder affects the bulbar musculature a variable pattern of spasticity and flaccidity compounded with weakness results. As about one-third of patients present with bulbar (lower motor neurone) and psudobulbar (upper motor neurone) palsy this is clearly an important problem. Apart from the difficulties in swallowing, progressive dysarthria in an intellectually normal patient may be very frustrating, particularly as weakness of the hands may lead to an inability to write, which cuts off all channels of communication. ${ }^{2}$

Previous work on speech patterns in motor neurone disease has concentrated on trying to assign specific patterns of speech and language symptoms characteristic of all patients with this disease at all stages of the disease. ${ }^{3}$ This study came to no important conclusion other than that the longer the disease progressed the more speech symptoms the patients had. Although all the abnormalities of articulation, voice production, and prosody have been well described, we were specially interested in assessing patients in order to choose a suitable speech aid from one of the many commercially available.

The aids available to us for this study were: Splink, Canon Communicator, Lightwriter, and Edu-Comm.

\section{Materials and methods}

PATIENTS

All the subjects had attended Charing Cross Hospital, had been diagnosed as having motor neurone disease, and had reported speech problems. Table I gives details of the patients.

TABLE I-Details of patients in study

\begin{tabular}{|c|c|c|c|c|c|c|}
\hline $\begin{array}{l}\text { Patient } \\
\text { No }\end{array}$ & Age & Sex & Onset & $\begin{array}{c}\text { Duration } \\
\text { of } \\
\text { disease } \\
\text { (months) }\end{array}$ & $\begin{array}{l}\text { Hands } \\
\text { usable }\end{array}$ & $\begin{array}{l}\text { Speech } \\
\text { intelligible }\end{array}$ \\
\hline $\begin{array}{r}1 \\
2 \\
3 \\
4 \\
5 \\
6 \\
7 \\
8 \\
9 \\
10 \\
11 \\
12 \\
13 \\
14 \\
15 \\
16\end{array}$ & $\begin{array}{l}59 \\
50 \\
56 \\
70 \\
61 \\
59 \\
53 \\
52 \\
29 \\
54 \\
64 \\
50 \\
60 \\
53 \\
67 \\
65\end{array}$ & $\begin{array}{l}F \\
M \\
M \\
F \\
F \\
F \\
F \\
M \\
M \\
M \\
F \\
F \\
M \\
F \\
F \\
F\end{array}$ & $\begin{array}{l}\text { December } 1977 \\
\text { October } 1977 \\
\text { January } 1979 \\
\text { July } 1978 \\
\text { March } 1979 \\
\text { April } 1979 \\
\text { March } 1978 \\
1975 \\
1977 \\
\text { March } 1979 \\
\text { October } 1978 \\
\text { April } 1979 \\
\text { July } 1978 \\
\text { September } 1978 \\
\text { October } 1979 \\
\text { August } 1980\end{array}$ & $\begin{array}{l}31 \\
33 \\
18 \\
24 \\
16 \\
15 \\
28 \\
48 \\
31 \\
16 \\
21 \\
15 \\
20 \\
22 \\
21 \\
2\end{array}$ & $\begin{array}{l}\text { Yes } \\
\text { Yes } \\
\text { Yes } \\
\text { Yes } \\
\text { Yes } \\
\text { Yes } \\
\text { No } \\
\text { No } \\
\text { No } \\
\text { Yes } \\
\text { Yes } \\
\text { Yes } \\
\text { Yes } \\
\text { Yes } \\
\text { No } \\
\text { Yes }\end{array}$ & $\begin{array}{l}\text { Yes } \\
\text { Yes } \\
\text { Yes } \\
\text { Yes } \\
\text { Yes } \\
\text { Yes } \\
\text { Yes } \\
\text { Yes } \\
\text { No } \\
\text { No } \\
\text { No } \\
\text { No } \\
\text { No } \\
\text { No } \\
\text { No } \\
\text { No }\end{array}$ \\
\hline
\end{tabular}

PROCEDURE

All the patients were assessed using the Frenchay dysarthria assessment ${ }^{4}-a$ test that includes evaluation and scoring of reflex actions, respiration, lips, jaw, palate, laryngeal action and tongue mobility, and rates overall intelligibility and rate of speech on repetition, oral description, and conversation.

The test takes an average time of 20 minutes to administer, each assessment being evaluated on a scale graded from 0 (no function) to 4 (normal).

We modified the original Frenchay as we thought that grading from 0 to 4 (rather than a, b, c, d) would describe the clinical changes in the patient more clearly. The patient's performance on all parts of the test are shown in table II; a shaded circle appears in the relevant column if the patient scored below 2 on that task-that is, that aspect of speech was severely affected.

\section{Aids}

The following aids were evaluated.

SPLINK

The Splink is a large word-board (42 $\mathrm{mm} \times 66 \mathrm{~mm}\left(16 \frac{1}{2}\right.$ in $\times 26 \frac{1}{2}$ in)) and microprocessor which are linked by infrared ray to a television set. The board consists of 950 basic words and letters in alphabetical order 
TABLE II-Results of dysarthria assessment test on each patient

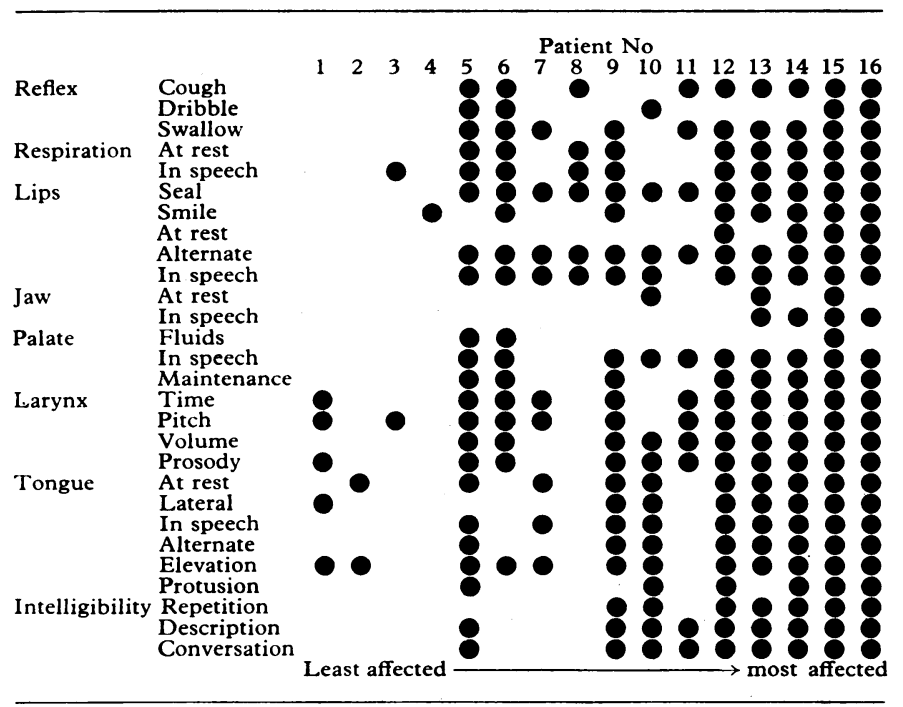

Aspect of speech severely affected.

together with phrases and numbers. The patient presses a key $(2 \mathrm{~mm} \times 1 \mathrm{~mm}(11 / 16 \mathrm{in} \times 5 / 16 \mathrm{in})$ for the required word, which is then emitted on the television screen. It is not portable as it needs a television to operate and demands good scanning ability and manual dexterity.

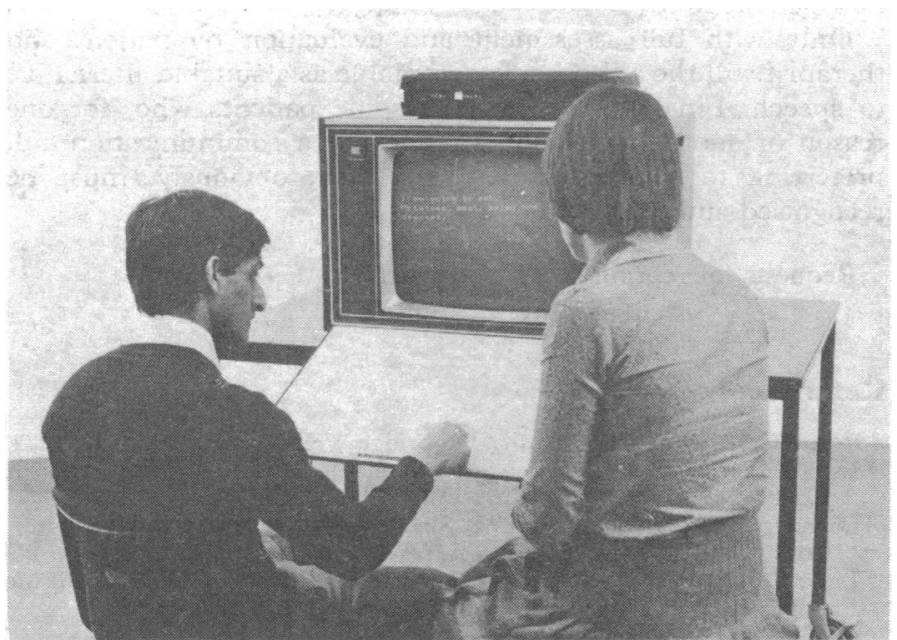

SPLINK consisting of communication board, microprocessor, and domestic television set.

\section{CANON COMMUNICATOR}

The Canon Communicator is a portable aid, the size of a pocket calculator, which has letters and a tickertape system. The patient spells letter by letter his needs, which are then printed on to the tape. The tape can then be torn and handed to the listener to read. Again, good visual ability and finger movement is needed. If the patient has difficulties with finger co-ordination it is possible to add an overlay to make contact with the letter keys more precise.

\section{LIGHTWRITER}

The Lightwriter is similar to a typewriter, but the keys light up on a small screen, which can be directed towards the person with whom one wishes to communicate. It operates electrically, and the keys are laid out in typeface fashion needing finger control.
EDU-COMM

The Edu-Comm consists of a light display board on which basic words are placed. The light can be moved by gross hand controls horizontally or vertically across 25 positions until the desired word is reached. It is suitable for expressing basic needs and wants, and can be operated by mouth with a pneumatic attachment.
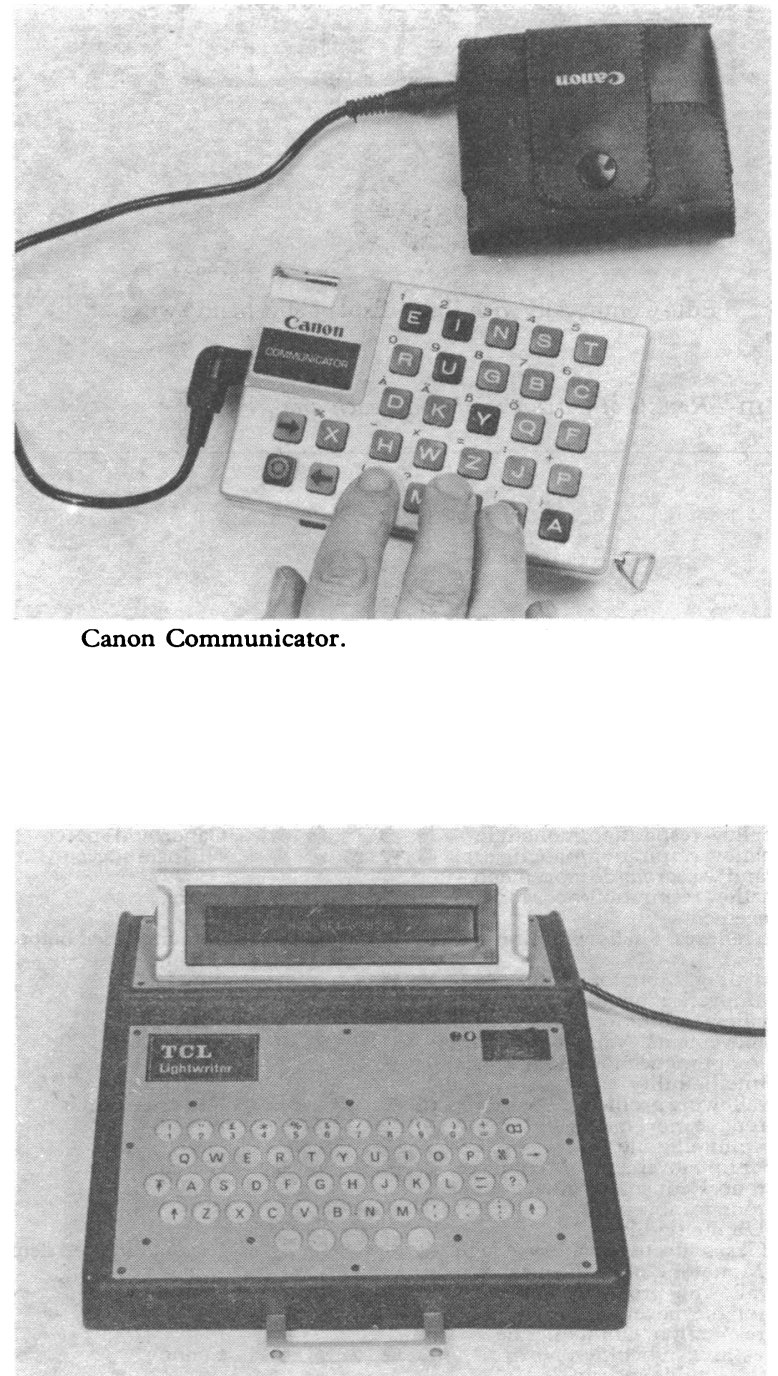

The Lightwriter with light display for communication.

\section{Assessment of aid suitability}

All patients were assessed for suitability with each of the four aids. They were allowed two weeks' clinical trial with each of the aids found most suitable and then asked to evaluate the usefulness of each and their preference. For some patients only one type of aid was suitable-usually this was the Edu-Comm as, owing to poor hand control, they needed the use of the pneumatic adaptor, which comes only with this aid. Table III gives the results of the trials with each aid.

\section{Assessment of speed}

Each patient was given six set phrases to practise in order to familiarise themselves with the aids. Patients were timed initially and at the end of the trial period (two weeks) to indicate the effectiveness of the aid for that patient's communication needs. The resulting speeds of communication (table IV) increased with practice. Some patients using aids were as fast as when using writing, and it required less effort for them to communicate. 


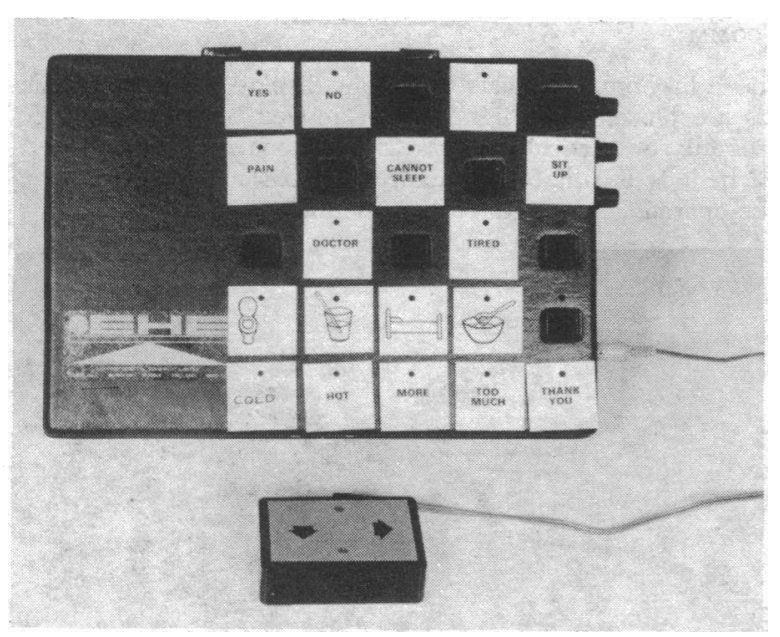

Edu-Comm Aid with light display and hand switch.

TABLE III-Results of patient trials with each aid

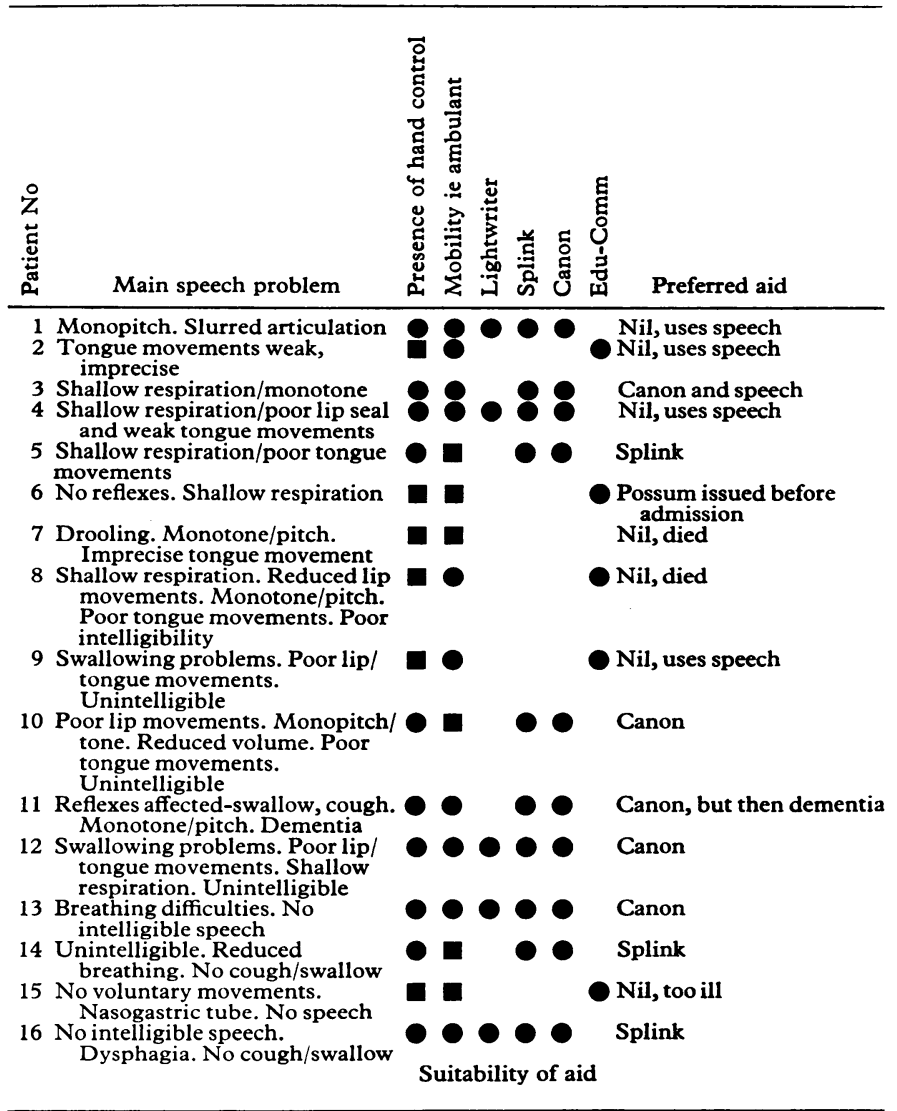

$\boldsymbol{\bullet}=$ Yes,

$\mathbf{Q}=$ No.

TABLE IV-Speed of communication with each aid

\begin{tabular}{|c|c|c|c|c|c|}
\hline $\begin{array}{c}\text { Patient } \\
\text { No } \\
\end{array}$ & Aid & \multicolumn{2}{|c|}{$\begin{array}{c}\text { Speed of } \\
\text { practised phrases (WPM) }\end{array}$} & \multicolumn{2}{|c|}{$\begin{array}{c}\text { Speed of } \\
\text { conversation (WPM) }\end{array}$} \\
\hline 3 & Canon & 6 & 12 & 5 & 9 \\
\hline 5 & Splink & 9 & 16 & 5 & 8 \\
\hline 10 & Canon & 8 & 12 & 7 & 8 \\
\hline 11 & Canon & 4 & 8 & 4 & 5 \\
\hline 12 & Canon & 10 & 20 & 11 & 15 \\
\hline 13 & Splink & 12 & 20 & 9 & 12 \\
\hline & Canon & 9 & 15 & 7 & 12 \\
\hline 14 & Splink & 5 & 10 & 6 & 7 \\
\hline 16 & Splink & 7 & 15 & 7 & 8 \\
\hline & Canon & 8 & 20 & 9 & 14 \\
\hline
\end{tabular}

WPM $=$ Words per minute.

\section{Discussion}

Although Splink and Canon Communicators were often suitable aids, the preference was usually for Canon if the patient was still mobile. Some patients, however, preferred the greater scope for "conversation" offered by Splink. One disadvantage of Splink was the relatively small area for each word and the large size of the board, but this could be partly overcome by reducing the number of words and increasing the size of the keys. Patients with even moderate hand and arm weakness found difficulty in reaching across the whole board but, with some modification, this aid might be suitable for more patients. These two aids were also more acceptableperhaps because they do not look like aids for the handicapped but more like pocket calculators (Canon) or a television game (Splink) and so have less stigma attached to them.

It would seem essential that a "library" of aids be available to patients so that a good choice may be offered and, as the disease progresses and manual dexterity diminishes, they may exchange one aid, which is no longer appropriate, for another that meets their needs more realistically.

Patients should practise with the various aids before they become totally dependent on them so that familiarity (and speed) is achieved early. This is particularly important because failure to achieve a reasonable speed may result in frustration when dependence on an aid occurs before a patient is familiar with it.

No one aid is suitable for all speech-impaired patients, and often the aid allocated is disliked and therefore not used. Hence a choice of available devices must be offered to any one individual. Although no one would contemplate offering patients the same size artificial limb, in matters of communication one often resorts to an aid that is available and tries to fit a patient to it.

Only with full assessment and evaluation by patient and therapist will the aid become acceptable as a suitable alternative to speech. Finally, there will be some patients who, for one reason or another, will not want to use a communication aid, preferring to remain mute. This wish, obviously, must be recognised and respected.

Requests for reprints to Mrs A R Perry.

\section{References}

${ }^{1}$ Rose FC. Motor neurone disease. Tunbridge Wells: Pitman Medical, 1977 2 Espir MLE, Rose FC. The basic neurology of speech. 2nd ed. Oxford: Blackwell, 1976

${ }^{3}$ Carrow E, Rivera V, Mauldin M, Shamblin L. Dviant speech characteristics in motor neurone disease. Arch Otolaryngol 1974;100:212-8.

4 Enderby P. Frenchay dysarthria assessment. Bristol:1979. (Available from author at Frenchay Hospital, Bristol.)

(Accepted 13 March 1981)

A patient develops an irritating rash when wearing "minimum iron" cotton shirts. As these are now universal what chemical is involved, and is there any process by which it can be removed? Repeated washing does not appear to help.

When repeated laundering fails to help an irritating rash from "minimum-iron" cotton shirts, the patient may have an allergic contact dermatitis from formaldehyde resin-treated fabric. ${ }^{1}$ Patch testing with pieces of fabric cannot be relied on to confirm the diagnosis. Patch testing with formaldehyde and formaldehyde resins is required, followed by chemical tests for formaldehyde on the patient's various shirt fabrics and subsequent avoidance of fabrics found to be positive. Once the skin has healed patients seem to tolerate garments identified as containing only small amounts of formaldehyde.

${ }^{1}$ Cronin E. Contact dermatitis. Edinburgh: Churchill Livingstone, 1980:56-66. 